\title{
PEMODELAN ANOMALI SELF-POTENTIAL GEOMETRI TETAP DAN INVERSI GLOBAL OPTIMASI VERY FAST SIMULATED ANNEALING
}

\author{
Hardi Hamzah $^{1, a}$, Mohammad Heriyanto ${ }^{2, b}$, Wahyu Srigutomo ${ }^{3, c}$ \\ ${ }^{1}$ Program Studi Pendidikan Fisika, Fakultas Keguruan dan Ilmu Pendidikan, Universitas Sulawesi Barat \\ Jl. Baharudin Lopa, Sulawesi Barat 91412, Indonesia \\ ${ }^{2}$ Jurusan Teknik Geofisika, Fakultas Teknologi Eksplorasi dan Produksi, Universitas Pertamina \\ Jl. Teuku Nyak Arief, Jakarta Selatan 12220, Indonesia \\ ${ }^{3}$ Jurusan Fisika, Fakultas Matematika dan Ilmu Pengetahuan Alam, Institut Teknologi Bandung \\ Jl. Ganesha No.10, Lb. Siliwangi, Coblong, Kota Bandung, Jawa Barat 40132, Indonesia \\ e-mail: 'hardi@unsulbar.ac.id, ${ }^{\mathrm{b}}$ mheriyanto@universitaspertamina.ac.id, ${ }^{\mathrm{c}}$ wahyu @ fi.itb.ac.id
}

\begin{abstract}
Abstrak
Penelitian ini membahas mengenai anomali SP geometri tetap pada pelat dan dilakukan inversi menggunakan global optimasi Very Fast Simulated Annealing (VFSA). Data yang digunakan adalah data sintetik hasil pemodelan. Hasil inversi menggunakan global optimlasi VFSA menunjukkan bahwa parameter model hasil inversi memiliki nilai yang hampir sama dengan nilai parameter model sintetik.
\end{abstract}

Kata kunci: Anomali SP, geometri tetap, VFSA

\section{FIXED SELF-POTENTIAL GEOMETRY ANOMALY MODELING AND VERY FAST SIMULATED ANNEALING GLOBAL OPTIMIZATION INVERSION}

\begin{abstract}
This research discusses the SP anomaly fixed geometry on the plate and inversion using global optimization Very Fast Simulated Annealing (VFSA). The data used is synthetic data from modeling results. The inversion results using global VFSA optimization show that the parameters of the inversion result model have a value that is almost the same as the parameter value of the synthetic model.
\end{abstract}

Keywords: SP anomly, fixed geometry, VFSA

\section{PENDAHULUAN}

Fisika merupakan ilmu alam yang mempelajari tentang sifat fisis dari materi. Salah satu kajian terpentingnya adalah di bidang geofisika. Sifat fisis yang dipelajari adalah sifat kelistrikan bumi, kemagnetan bumi, penjalaran gelombang, dan gravitasi. Pengukuran sifat fisis bumi dilakukan di permukaan sehingga memberikan gambaran mengenai kondisi di bawah permukaan.

Salah satu teknik pengukuran yang dapat dilakukan adalah metode self-potential (SP). Metode ini merupakan metode pengukuran pasif memanfaatkan potensial diri yang dihasilkan secara alami di bawah permukaan. Beda potensial ini disebabkan oleh aliran fluida, biolektrik akibat organisme, konsentrasi larutan elelktrolit air tanah, dan reaksi geokimia pada zona mineralisasi [1].

Metode self-potential adalah metode geofisika pasif, seperti gravitasi dan metode magnetik. Metode ini melibatkan pengukuran potensial listrik pada sejumlah titik pengukuran disebut stasiun selfpotential. Hasil pengukuran yang diperoleh 
dapat memberikan informasi penting mengenai aliran air tanah, hydromechanical, dan gangguan geokimia [2].

Metode SP diterapkan pada survei air geothermal, delineasi zona geser, patahan dekat permukaan, dan anomali di bawah permukaan tanah. [3] Pernah melakukan penelitian mengenai struktur patahan di Desa Pinggirsari Kecamatan Arjasari Kabupaten Bandung Jawa Barat.

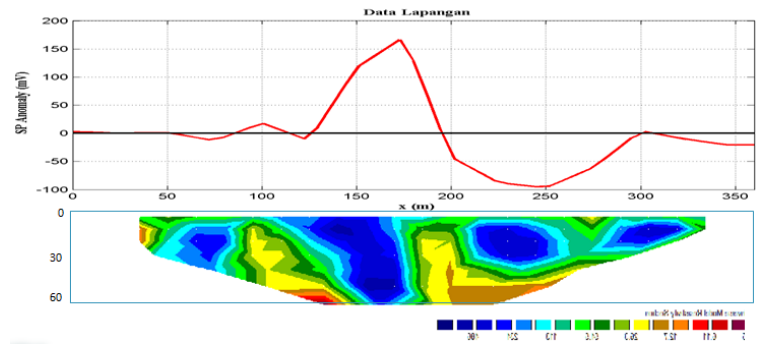

Gambar 1. Anomali self potential yang terukur di permukaan dan distribusi resistivitas di bawah permukaan hasil inversi

Diperoleh hasil pengukuran anomali SP di permukaan seperti terlihat pada gambar 1. Terlihat bahwa anomali self potential bernilai positf ratusan milivolt berada pada interval pengukuran $150 \mathrm{~m}$ sampai dengan $200 \mathrm{~m}$. Anomali self potential bernilai negatif ratusan milivolt pada interval pengukuran $225 \mathrm{~m}$ sampai dengan $275 \mathrm{~m}$. Anomali self potential positif lebih besar dari nilai negatif. Hal ini menunjukkan bahwa akumulasi nilai dekat permukaan lebih positif dibanding dengan yang berada jauh dari permukaan. Berdasarkan informasi geologi, pola anomali SP ini berasosiasi dengan keberadaan sesar.

Analisis kuantitatif geometri tetap pernah dimodelkan pada anomali gravitasi.
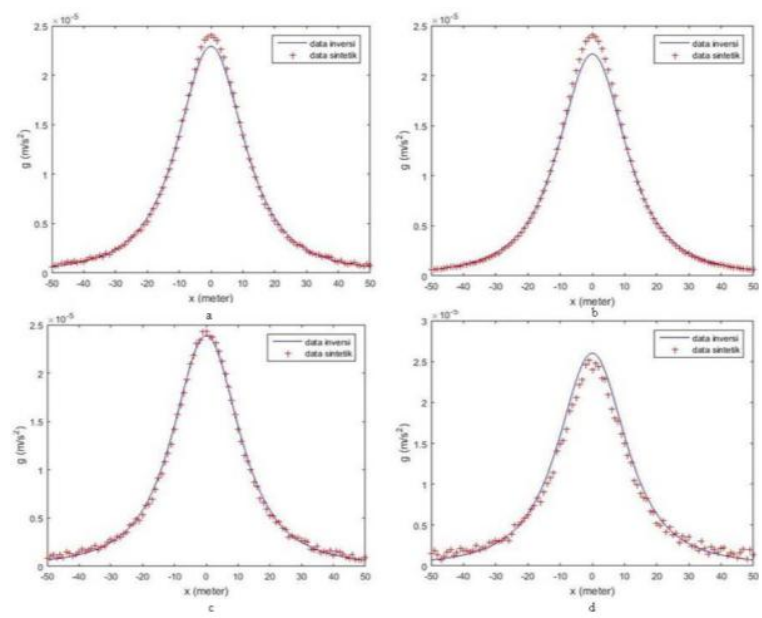

Gambar 2. Hasil inversi nonlinear metode least square

Gambar memperihatkan data sintetik dan data hasil inversi hampir saling berimpit. Noise $1 \%$ diberikan pada data sintetik kemudian diinversi dan diperoleh hasil seperti terlihat pada gambar 2.a. Noise 5\%, $10 \%$, dan $20 \%$ diberikan, diperoleh hasil berturut seperti pada gambar 2.b, 2.c, dan 2.d. Diperoleh data hasil inversi yang hampir berimpit dengan data model sintetik. Jadi, pemberian noise tidak memberkan pengaruh yang signifikan terhadap hasil inversi [4].

Interpretasi anomali SP di atas sebuah struktur miring 2D telah diteliti oleh [5] bentuk struktur miring tersebut ditunjukkan pada gambar berikut

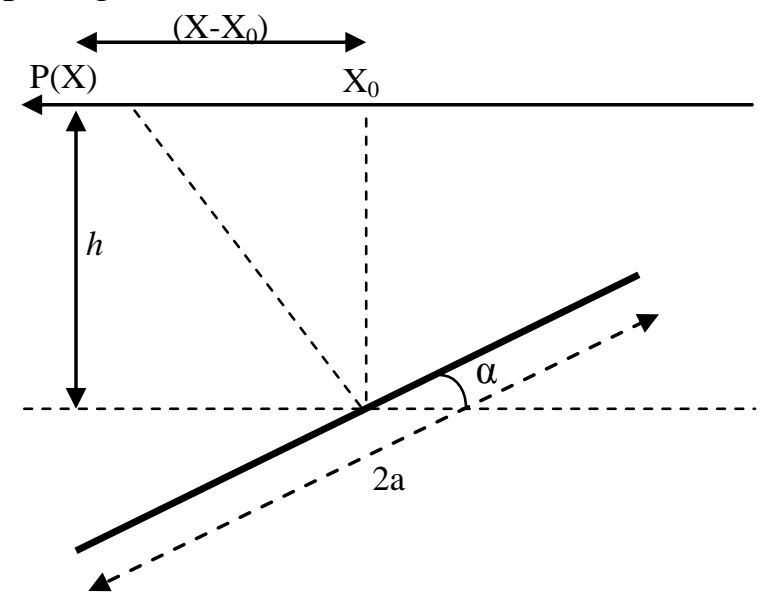




\section{Gambar 3. Geometri Pelat Miring Horisontal Takberhingga}

Ada lima parameter model dari tipe struktur lempeng pada Gambar 3 yaitu rapat dipole listrik $k=I \rho / 2 \pi$ ( $I$ adalah rapat arus dari medium dan $\rho$ adalah resistivitas dari plat), $x$ adalah koordinat dari pusat plat $x_{0}, h$ adalah kedalaman pusat plat, $a$ adalah setengah lebar plat, dan $\alpha$ adalah sudut kemiringan plat. Bentuk anomali SP yang terukur di permukaan adalah

$V(x)=k \ln \frac{\left[\left(x-x_{0}\right)-a \cos \alpha\right]^{2}+(h-a \sin \alpha)^{2}}{\left[\left(x-x_{0}\right)+a \cos \alpha\right]^{2}+(h+a \sin \alpha)^{2}}$

Pada penelitian ini akan dibahas mengenai anomali SP geometri tetap pada pelat dan dilakukan inversi menggunakan global optimasi Very Fast Simulated Annealing (VFSA). Metode VFSA banyak diterapkan pada bidang geofisika, seperti: untuk interpretasi anomali gravitasi dan magnetik [6], kalibrasi kecepatan untuk microseismic monitoring [7], hybrid optimasi untuk inversi geofisika dengan menggabungkan metode Conjugate Gradient (CG) dan VFSA [8], dan interpretasi anomali SP 2-D [9]. Aturan penerimaan dari algoritma ini sama dengan yang digunakan di Metropolis SA [10].

Tujuan penelitian ini adalah untuk memodelkan anomali SP geometri tetap pada pelat dan menginversi menggunakan global optimasi VFSA dan melihat pengaruh kedalaman, posisi koordinat, momen dipole listrik, sudut polarisasi, dan faktor bentuk terhadap anomali SP.

\section{METODE}

\section{Tahap Penelitian}

Tahapan-tahapan dalam penelitian ini adalah sebagai berikut:

\begin{tabular}{|c|c|c|}
\hline No. & $\begin{array}{c}\text { Tahap } \\
\text { Penelitian }\end{array}$ & Keterangan \\
\hline 1. & $\begin{array}{l}\text { Memodelkan } \\
\text { Permasalahan }\end{array}$ & $\begin{array}{l}\text { Membuat model } \\
\text { matematika untuk } \\
\text { permasalahan } \\
\text { anomali SP }\end{array}$ \\
\hline 2. & $\begin{array}{l}\text { Membuat } \\
\text { flowchart }\end{array}$ & $\begin{array}{l}\text { flowchart yang } \\
\text { dibuat adalah } \\
\text { proses inversi dan } \\
\text { memperbaharui } \\
\text { parameter model }\end{array}$ \\
\hline 3. & $\begin{array}{l}\text { Membuat model } \\
\text { sintetik }\end{array}$ & $\begin{array}{lr}\text { model } & \text { sintetik } \\
\text { dibuat } & \text { terlebih } \\
\text { dahulu } & \text { untuk } \\
\text { menguji } & \text { program } \\
\text { inversi } & \text { global } \\
\text { optimasi } & \text { VFSA }\end{array}$ \\
\hline 4. & $\begin{array}{l}\text { Menginversi } \\
\text { data sintetik }\end{array}$ & $\begin{array}{l}\text { setelah tahap } \\
\text { pengujian } \\
\text { berhasil, } \\
\text { digunakan data } \\
\text { sintetik yang akan } \\
\text { diinversi. }\end{array}$ \\
\hline
\end{tabular}

\section{Jenis Penelitian}

Penelitian adalah penelitian kuantitatif dengan teknik pemodelan anomali SP geometri tetap dan inversi global optimasi VFSA

\section{Waktu dan Tempat Penelitian}

Penelitian akan dilakukan di laboratorium komputer menggunakan MATLAB R2015a.

\section{Target/Subjek Penelitian}

Peubah yang akan diamati dalam penelitian ini adalah respon parameter model menggunakan global optimasi VFSA. 


\section{Data, Intrumen, dan Teknik Pengumpulan Data}

Data yang akan digunakan dalam penelitian ini adalah data sintetik hasil pemodelan.

\section{Teknik Analisis Data}

Analisis data yang digunakan adalah global optimasi VFSA. Aturan penerimaan dari algoritma ini sama dengan yang digunakan di Metropolis SA, dan algoritma ini disebut Very Fast Simulated Annealing (VFSA). VFSA atau tehnik optimisasi global memiliki rentang pencarian $\left(P_{i}^{\min }\right.$ dan $P_{i}^{\max }$, nilai minimum dan nilai maksimum ke i parameter dalam ruang model). Formulasi

$$
y_{i}=\operatorname{sgn}\left(u_{i}-0.5\right) T_{i}\left(\left(1+\frac{1}{T_{i}}\right)^{\left|2 u_{i}-1\right|}-1\right)
$$

digunakan untuk Updating factor $y_{i}$ parameter ke i dihitung menggunakan berikut, yang bervariasi antara -1 dan 1. $u_{i}$ adalah bilangan random seragam bervariasi antara 0 dan 1 , dan $T_{i}$ adalah temperatur. Setiap parameter $P_{i}$ diperbaharui menjadi $P_{i}^{j+1}$ dari nilai sebelumnya $P_{i}^{j}$ menggunakan rumus

$P_{i}^{j+1}=P_{i}^{j}+y_{i}\left(P_{i}^{\max }-P_{i}^{\min }\right)$

sehingga model baru diperoleh, Kemudian, misfit disesuaikan dengan model kalkulasi lalu dibandingkan dengan misfit model sebelumnya. Jika misfit model ini kurang dari misfit model awal, maka model baru dipilih dengan probabilitas $\exp (-\Delta \varphi / T)$. $\Delta \varphi$ adalah perbedaan misfit kedua model. Apabila misfit model baru lebih besar dibandingkan model sebelumnya, maka bilangan random ditarik dan dibandingkan dengan probabilitas. Jika probabilitas lebih besar dari bilangan random yang ditarik, maka, model baru diterima dengan probabilitas sama, dan sebaliknya model ini ditolak. Bilangan yang diinginkan bergerak pada tingkat suhu yang sama dengan menerima atau menolak model baru sesuai dengan kriteria yang disebutkan di atas. Ini melengkapi satu iterasi. Gerakan dalam ruang model pada satu tingkat suhu menghasilkan model perbaikan. Setelah menyelesaikan bilangan yang dikehendaki bergerak pada suhu tertentu, suhu dikurangi ke tingkat yang lebih rendah sesuai dengan formula pendinginan berikut

$T_{i}(j)=T_{0 i} \exp \left(-c_{i} j^{\frac{1}{M}}\right)$

$j$ adalah iterasi terakhir, $c_{i}$ adalah konstanta yang mungkin berbeda untuk parameter model yang berbeda, dan $T_{0 i}$ adalah temperatur awal, yang mungkin berbeda untuk parameter model yang berbeda dan bergantung pada sifat dari misfit dipertimbangkan untuk optimasi. Dalam penelitian ini, $c_{i}$ dianggap sama dengan 1 dan suhu awal telah diambil sebagai 1.0.

\section{HASIL DAN DISKUSI}

Persamaan 1 digunakan untuk memodelkan permasalahan yang dikaji dengan $k, x_{0}, h, a$, dan $\alpha$ adalah parameter model yang tidak diketahui dari tipe struktur plat. Pada penelitian ini, dipilih nilai $k=50 \mathrm{mV}$, pelat diletakkan pada jarak $x_{0}=200 \mathrm{~m}$, pada kedalaman $h=40 \mathrm{~m}$, dengan setengah lebar plat $a=50 \mathrm{~m}$, dan sudut kemiringan $\alpha=30^{\circ}$. Diperoleh hasil pemodelan seperti pada gambar berikut 


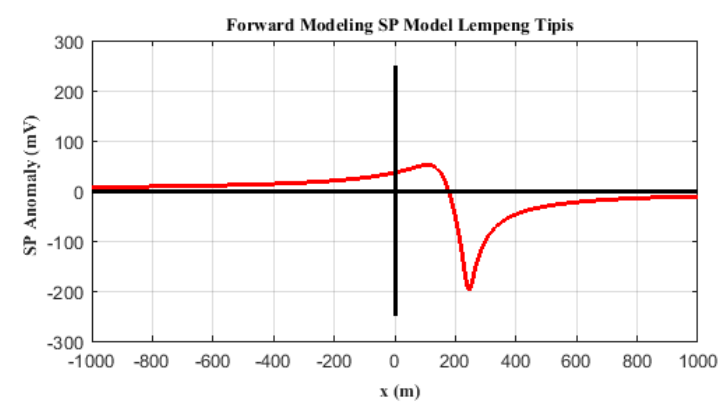

Gambar 4. Hasil Pemodelan

Nilai anomali SP pada jarak $1000 \mathrm{~m}$ disebelah kiri titik nol adalah $0 \mathrm{mV}$, semakin ke kanan nilai ini mula-mula tidak ada perubahan yang signifikan, kemudian terjadi kenaikan nilai anomali SP pada jarak $400 \mathrm{~m}$ di sebelah kiri titik nol dan nilai puncak anomali SP Ketika mendekati jarak 200 m di selah kanan titik nol. Kemudian nilai anomali SP menurun secara signifikan dan puncaknya disebelah kanan jarak $200 \mathrm{~m}$ dari titik nol lalu naik lagi hingga pada jarak $1000 \mathrm{~m}$ di sebelah kanan titik nol nilainya menuju $0 \mathrm{mV}$. Hal ini disebabkan karena keberadaan pelat yang diletakkan pada jarak $200 \mathrm{~m}$ disebelah kanan titik nol sehingga anomali SP yang terkur dipermukaan terjadi di sekitar titik ini.

Data anomali SP dari pemodelan ini dijadikan data sintetik lalu di inversi. Parameter model yang dipilih adalah $k, a$, dan sudut $\alpha$. Hasil inversi yang diperoleh seperti pada gambar berikut

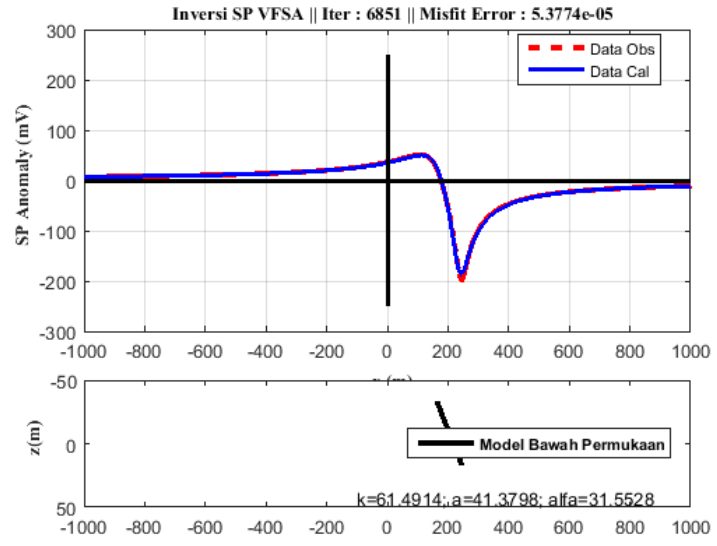

Gambar 5. Hasil Inversi Global Optimasi VFSA
Gabar 5 menunjukkan bahwa data kalkulasi (warna biru pada gambar) dan data observasi (warna merah pada gambar) terlihat berimpit dengan misfit error 5,3744 $10^{-5}$. Nilai parameter model hasil inversi yaitu $k=61.4914 \mathrm{mV}, a=41,3798 \mathrm{~m}$, dan sudut kemiringan $\alpha=31,5528^{\circ}$ hampir sama dengan nilai parameter model yang sebenarnya.

\section{SIMPULAN DAN SARAN}

\section{Simpulan}

Hasil inversi menggunakan global optimlasi VFSA telah berhasil dilakukan. Parameter model hasil inversi menunjukkan nilai yang hampir sama dengan nilai parameter model sintetik.

\section{Saran}

Hasil penelitian ini dapat diuji menggunakan data lapangan.

\section{DAFTAR PUSTAKA}

[1] Telford, W.M., Geldart, L.P., and Sheriff, R.E. Applied Geophysics. 2th Edition. 1990. Cambridge: Cabridge University Press

[2] Revil A., Jardani A., The SelfPotential Method Theory anf Aplication in Environmental Geoscience. 1th Edition.2013. Cambridge: Cabridge University Press

[3] Hamzah, H. dan Srigutomo, W. Pemodelan Kedepan dan Inversi 2D Self-Potential Menggunakan Metode Elemen Hingga dan Optimasi Global Very Fast Simulated Annealing.Tesisi.Tidak

Dipublikasikan. Bandung : Institut Teknologi Bandung.2016

[4] Hamzah, H., Mutmainnah., Analisis Kuantitatif Anomali Gravitasi Metode Least Square pada Terapan Mata Kuliah Analisa Numerik. 2018:4(1): 24-30.

DOI:10.31605/saintifik.v4i1.140

[5] Sharma, S.P., Biswas, A., Interpretation of self-potential anomaly over a 2D inclined structure 
using very fast simulated-annealing global optimization - An insight about ambiguity. 2013:78(3):WB3WB15. DOI :10.1190/geo2012-0233.1

[6] Biswas, A., Interpretation of gravity and magnetic anomaly over thin sheettype structure using very fast simulated annealing global optimization technique. 2016:(2:30):112.DOI: 0.1007/s40808-016 0082-1

[7] Pei, D., Quirein, J.A.,Comish, B.E., Quinn, D.,Warpinski, N.R. Velocity calibration for microseismic monitoring: A very fast simulated annealing (VFSA) approach for jointobjective optimization. 2009:74(6):WCB47-WCB55.DOI: 10.1190/1.3238365

[8] Chunduru, R.K.,Sen, M.K.,Stoffa, P.L.Hybrid geophysical inversion.1997:62(4):1196-1207. http://library.seg.org/

[9] Biswas, P., Sharma, S.P., Interpretation of self-potential anomaly over 2-D inclined thick sheet structures and analysis of uncertainty using very fast simulated annealing global optimization. 2017:52(4):439455.

https://link.springer.com/article/10.100 7/s40328-016-0176-2

[10] Sen, K.M.,Stoffa, P.L., Global optimization method in Geophysical Inversion. 2th edition. Cambridge: Cambridge University Press. 